\title{
Climate windows of opportunity for plant expansion during the Phanerozoic
}

\author{
Khushboo Gurung ( $\nabla$ bskgu@leeds.ac.uk ) \\ University of Leeds https://orcid.org/0000-0001-8074-7339 \\ Katie Field \\ University of Sheffield
}

Sarah Batterman

Cary Institute of Ecosystem Studies

\section{Yves Godderis}

Geoscience Environnement Toulouse https://orcid.org/0000-0002-6054-614X

\section{Yannick Donnadieu}

CEREGE https://orcid.org/0000-0002-7315-2684

\section{Philipp Porada}

University of Hamburg https://orcid.org/0000-0002-5072-0220

\section{Lyla Taylor}

University of Sheffield https://orcid.org/0000-0002-3406-7452

\section{Benjamin Mills}

University of Leeds https://orcid.org/0000-0002-9141-0931

\section{Article}

\section{Keywords:}

Posted Date: December 10th, 2021

DOI: https://doi.org/10.21203/rs.3.rs-1104079/v1

License: (c) (1) This work is licensed under a Creative Commons Attribution 4.0 International License. Read Full License

Version of Record: A version of this preprint was published at Nature Communications on August 4th, 2022. See the published version at https://doi.org/10.1038/s41467-022-32077-7. 


\section{Climate windows of opportunity for plant expansion during the}

2 Phanerozoic

3 Khushboo Gurung ${ }^{1,2}$, Katie J. Field ${ }^{3}$, Sarah A. Batterman ${ }^{4}$, Yves Goddéris ${ }^{5}$, 4 Yannick Donnadieu ${ }^{6}$, Philipp Porada ${ }^{7}$, Lyla L. Taylor ${ }^{3}$, Benjamin J. W. 5 Mills $^{2}$

6

$7 \quad{ }^{1}$ Centre for Plant Sciences, School of Biology, University of Leeds, Leeds LS2 9JT, UK

$8 \quad{ }^{2}$ School of Earth and Environment, University of Leeds, Leeds LS2 9JT, UK

9 '3Plants, Photosynthesis and Soil, School of Biosciences, University of Sheffield, Sheffield, S10 2TN UK

$11{ }^{4}$ Cary Institute of Ecosystem Studies, Millbrook, NY 12545

12 ' ${ }^{5}$ Géosciences Environnement Toulouse, CNRS-Université de Toulouse III, Toulouse, France

$13 \quad{ }^{6}$ CEREGE, Aix Marseille Univ, CNRS, IRD, INRA, Coll France, Aix-en-Provence, France

14 Institute of Plant Science and Microbiology, University of Hamburg, Germany

Contributions

$\mathrm{KG}, \mathrm{KJF}, \mathrm{SAB}$ and BJWM conceived and designed the investigation. KG wrote the model, analysed the data and wrote the first draft of the manuscript with assistance from KJF and BJWM. YG, YD, PP and LLT provided data and discussed results. All authors discussed results and commented on the manuscript. $\mathrm{KG}$ agrees to serve as the author responsible for correspondence. 
Plants are likely to have had a profound influence on Earth's long-term climate through their soils and minerals. Local climatic factors, including water availability, light, and temperature, play a key role in plant physiology and growth and have fluctuated substantially over geological time. However, the impact of these key climate variables on global plant biomass across the Phanerozoic have not yet been established.

\section{Introduction} point in Earth history, with profound impacts on the planet's surface chemistry and climate ${ }^{1}$. The earliest land plants (embryophytes) are first identified in the Ordovician period and are morphologically simple compared to modern vascular plants, being rootless and nonvascular, and bearing some similarities to bryophytes ${ }^{2}$. Throughout the Paleozoic, terrestrial flora diversified with vascular plants (tracheophytes) first being recorded during the late Silurian and radiating in the Devonian ${ }^{3}$. Continuous adaptation to the local environment over time drove the evolution of stems, leaves, wood and bark in the late Devonian and Early Carboniferous $^{3}$. A later major step in plant evolution was the divergence of the angiosperms (flowering plants), estimated to have occurred between 120-100 Ma based on the occurrence terrestrial plant assemblages throughout the remainder of the Cretaceous.

Plants likely had dramatic impacts on the composition of the atmosphere by drawing down and photosynthetically fixing atmospheric $\mathrm{CO}_{2}$ into organic biomolecules, and by altering the continental weathering processes which are a key part of most major 
biogeochemical cycles ${ }^{5,6}$. Through their influence on atmospheric composition and biogeochemical cycles, it has been hypothesised that plants had a key role in driving both the Hirnantian ( 445 Ma) and Late Paleozoic ( 300 Ma) ice ages ${ }^{6,7}$ as well as mid-Paleozoic oxygenation of the atmosphere ${ }^{8}$ and the more recent Cenozoic cooling ${ }^{9,10}$. However, while the general trajectory of plant evolution is relatively well understood, it remains difficult to estimate a key factor for the magnitude of any climate or biogeochemical effects: global plant biomass and productivity. The methods of quantification and modelling of the land biosphere in the above cited work tend to rely on either box modelling, with no consideration of global hydrology and the impact of water availability on key plant physiological processes ${ }^{6,7,11}$, or on complex spatial vegetation models which are set up for specific time periods and are not easily extended across Phanerozoic time ${ }^{8,12}$.

Earth's paleogeography is a key feature that regulates plant productivity and biomass at the global scale as it modulates local hydrology and temperature ${ }^{13,14}$. Conditions dictated by changes in paleogeography therefore can enhance or diminish plant growth and could have been a key factor in the expansion of new plant groups and species ${ }^{15}$. One of the biggest changes in paleogeography during the Phanerozoic was the breakup of the supercontinent Pangea (Figure S1) which saw the transition away from an Earth surface where runoff was limited due to the reduction of inland rainfall ${ }^{16}$. The breakup of the supercontinent and the subsequent enhancement of the hydrological cycle via the formation of a new ocean ${ }^{17}$ may have led to the expansion of temperate zones and introduced new niches which could have promoted angiosperm radiation during the Cretaceous ${ }^{14}$. Despite these important hypotheses, there has been relatively little exploration of emergent vegetation dynamics under past climates. The most progress to date has been achieved through use of the Sheffield Dynamic Global Vegetation Model (SDGVM) but this has been restricted to post-Pangaea climates ${ }^{12,18}$. 
Here, we developed a simplified deep-time dynamic global vegetation model which can easily be run for a variety of past climates throughout the Phanerozoic to test the hypothesis that paleogeography itself has influenced the spread of plants across Earth's terrestrial land masses. We validate our model against present day distribution of vegetation and the previous SDGVM work, and explore the effect of Phanerozoic continental dispersion, temperature and runoff on the potential for the Earth to host plant biomass.

Our deep-time vegetation model is called FLORA: Fast Land Occupancy and Reaction Algorithm. This acronym embodies the key considerations of the model; computational speed, the ability to determine if each land grid cell in a climate model is suitable for plant growth, providing an estimate of the total productivity and biomass for each cell through modelling the photosynthesis and respiration reactions. Our model is largely simplified from the Lund-Postdam-Jena DGVM (LPJ-DGVM) ${ }^{19}$ and captures the flow of carbon from its atmospheric form $\left(\mathrm{CO}_{2}\right)$ to storage as biomass in plants (Figure 1). The advantage of this simplification is that FLORA can be run very quickly and in-line with larger biogeochemical frameworks while retaining very predictions of vegetation carbon distribution to those of the LPJ-DGVM (Sitch et al., 2003).

We define Net Primary Productivity (NPP) as the net carbon stored after autotrophic respiration ${ }^{20}$. We assume that all plant carbon within the system is stored in the form of leaf biomass for simplicity. Although root and sapwood biomass are present within the LPJDGVM ${ }^{19}$, they are closely linked to the other biomass pools and are not required to reproduce a reasonable fit to modern biomass (see validation below). Moreover, these features were absent from early plants, thus we opt for the simplest approach. The methods section outlines the equations that dictate the rate of photosynthesis and respiration, carbon allocation and turnover as a response to local solar insolation, temperature and water availability, as well as to the atmospheric $\mathrm{CO}_{2}$ and $\mathrm{O}_{2}$ levels. 

continental surface, and for three basic plant functional types: tropical, boreal and temperate.

The only distinction between each plant functional type is their performance at different temperatures ${ }^{21}$; each plant functional type has a different optimum temperature for photosynthesis (Table S1). A simple competition model for each grid cell allows only the contribution of the functional type for which the highest potential biomass is calculated, thus dictating the 'biome' of the grid cell.

We ran FLORA subject to boundary conditions of the preindustrial $\mathrm{CO}_{2}$ and $\mathrm{O}_{2}$ levels, 0.5 degree gridded global runoff ${ }^{22}$ and temperature ${ }^{23}$ measurements, and a standardised insolation curve peaking at $400 \mathrm{~W} / \mathrm{m}^{2}$ at the equator ${ }^{24}$. Despite the simplicity of the model, the predicted global pattern of biomass shows good agreement with the measured global biomass (Figure 2) ${ }^{25}$. The largest errors occur in the tropics but vary from overprediction in South Asia and Indonesia, to under-prediction in tropical Africa. The maximum error in a single grid cell is about $2 \times 10^{4} \mathrm{gC} / \mathrm{m}^{2}$, but errors tend to be balanced when considering larger areas (Figure 3). Our model also tends to slightly over-represent biomass in the northern high mid-latitudes and under-represent biomass in the southern high midlatitudes.

Figure 3 shows the longitudinal and latitudinal biomass comparisons and the relationship between the model and the global database ${ }^{25}$. These highlight that the model has reasonable capabilities in capturing the key trends, and again show the slight over-prediction of biomass in South-East Asia and under-prediction in tropical Africa. These differences may be attributable to the yearly-averaged datasets that are used as forcings. For example, seasonal changes in runoff and productivity are not captured which means monsoonal climates are not well-represented. Overall, we consider the model to be appropriate to the 
task it is designed for. It suitably reconstructs the major patterns of plant biomass on the present-day Earth.

\section{Results \& Discussion}

\section{Potential plant biomass over the Phanerozoic}

FLORA was run for the paleogeography, surface air temperature and runoff calculated by Godderis et al. (2014) using the FOAM (Fast Ocean Atmosphere Model ${ }^{26}$ ) climate model for 22 time points over the Phanerozoic. We set the $\mathrm{CO}_{2}$ concentration for each run based on proxy information, and box modelling where proxies are unavailable (Table S2). For these runs we do not consider any evolutionary changes in the land biosphere, thus our calculation is for 'potential biomass' under our generalised photosynthesis respiration model with modern plant functional types. The intention here is to understand the biomass potential of past climates based on fundamental photosynthetic processes and parameters. Our results are shown in Figure 4 and Figure 5 alongside model parameters: area, runoff, $\mathrm{CO}_{2}$ level and average temperature of each climate model run. These results indicate two clear peaks in potential biomass; the first being during the Ordovician, and the second being a broader peak from the Jurassic to the Paleogene Figure 5A).

The peaks in potential biomass predicted by our model are consistent with times of generally elevated global runoff (Figure 5A and D), which is understandable given the absolute requirement for water for plant growth. Runoff also has the highest average $\mathrm{r}$ squared value across all time points (0.72; Figure S2) suggesting potential biomass is most influenced by water availability. There is also some correlation between potential biomass with temperature, where the expansion of ice caps during the late Paleozoic and the late Cenozoic limited the habitable space, but very warm climates like the late Cretaceous also 
limited productivity. Our findings compare well to those of Taylor et al. (2012), who coupled the SDGVM to the Hadley Centre general circulation model (HadCM3L) for a more limited set of paleoclimates. They also found high reconstructed global biomass across the Cretaceous and Paleogene. The large disparity seen in the Cenomanian appears to be due to differences in the exposed land area in the tropics between the climate model runs. The modelling of Taylor et al. (2012) assumes a large exposed African continent in the tropics whereas the reconstruction used in FOAM for this work has much of the continent flooded. Nevertheless, both the previous work, and our new analysis agree that the breakup of Pangaea (Figure S1) was accompanied by a substantial increase in the habitable space available for plants.

\section{Possible links between climate and plant evolution}

Our results show an early peak in potential biomass at around $470 \mathrm{Ma}$ (Figure 5A) suggesting temperature and water availability were optimal for plant productivity at this time. During this time period there was substantial low-latitude land mass which was sufficiently dispersed to maintain a strong hydrological cycle, continental temperatures were also warm and there were no permanent ice caps (e.g. Scotese et al., 2021). Embryophytes and other morphologically simple plants present during the Ordovician lacked specialised vascular tissues such as roots or stems ${ }^{2}$ that are typically associated with water conduction. These early plants likely existed mostly in equilibrium with surrounding air ${ }^{28}$ and their distributions were largely restricted to environments of high water availability. Despite many modern bryophytes displaying poikilohydry, the water desiccation tolerance of early land plants remains unknown, and colonisation of more arid, inland environments would require morphological and physiological strategies to prevent plant water loss. According to the 
FOAM climate model runs, global runoff was increasing between 540-470 Ma (Figure 5D).

This increase in water availability on land would allow for the increasing productivity on land surface during the Ordovician, allowing early plants ${ }^{28}$ to persist on land with minimal risk of dehydration. As the optimal plant growth conditions became more widely distributed global plant productivity is likely have increased in tandem.

In our model, the favourability of the land surface to plant growth decreases throughout the post-Ordovician Paleozoic. Precipitation and runoff decrease markedly as the amalgamation of Pangaea is completed, and the effects of the cooling in the late Paleozoic also reduced the habitable space for plants. Silurian mesofossils indicate the presence of lignified cell walls and tubular structures essential for water supply tow ards the peripheral regions of plants which were further developed towards the Devonian ${ }^{29}$. Tracheophytes evolved between around $450-430 \mathrm{Ma}^{30}$ and the evolution of roots also fall between the Silurian-Devonian period, beginning with rhizoid structures and ending with extensive rooting systems ${ }^{31,32}$. Thus, this period of increasing aridity is associated with the circular evolution of morphological and physiological innovations in plants, focused towards water acquisition, transport and retention.

The oldest angiosperm fossil is dated to $136 \mathrm{Ma}^{33}$, but molecular clocks suggest the early history of angiosperms is cryptic ${ }^{34}$, with diversification potentially as early as 195-246 $\mathrm{Ma}^{30}$. In our model, potential biomass shows a significant increase around $200 \mathrm{Ma}$ which is sustained until the Neogene (Figure 5A). This increase in plant habitability is strongly linked to a large rise in global precipitation and runoff following the breakup of Pangea. During this time, equatorial Pangea transitioned from arid conditions to a 'megamonsoonal' circulation which has previously been proposed to set the stage for the ecological expansion of flowering plants ${ }^{14}$. The separation of land creates a water cycle in areas that previously were arid ${ }^{35}$ and the spread of land around the equator increases the land area experiencing high-moderate 
temperatures for plant growth. Thus, our work supports the inference of a large expansion of habitable space for plants being linked to the mid-late Mesozoic angiosperm radiation.

\section{Conclusion}

3

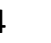

$$
\text { Global plant biomass is controlled by a combination of surface air temperature, }
$$
hydrology and photosynthetically-active radiation, and our simple model, FLORA, based on these factors can reproduce a fair representation of present-day biomass distribution (Figure 3). In Earth's past, these factors have changed markedly due to the positioning of the continents and changes in radiative forcing. When we run FLORA under the FOAM climate model outputs, we find two clear peaks in the 'potential biomass' - a measure of the Earth surface's ability to host plant life. This analysis shows a strong environmental incentive for plant expansion during the Ordovician and a later window during the Jurassic-to-Paleogene, which correspond with the initial land colonisation and the major radiation of Angiosperms respectively. Moreover, the Silurian-Devonian saw increasing aridity, correlating with a succession of plant adaptions in favour of water transport and retention. We propose that these windows of opportunity played a key part in initiating these evolutionary expansions.

6


Most equations are directly taken or slightly altered from equations 1-25 in Sitch et al. 2003 and equations 4-26 from Haxeltine \& Prentice, 1996. Photosynthesis rate, $P$ (g

$227 \mathrm{C} / \mathrm{m}^{2} /$ year) is given by:

$$
P=3650 \text { ins }\left(\frac{c_{1}}{c_{2}}\right)\left[c_{2}-(2 \theta-1) s-2\left(c_{2}-\theta s\right) \sigma_{c}\right] \omega
$$

228

229

230

231

232

233

where photosynthesis is scaled by water stress, $\omega$ and insolation, ins. $\omega$ is calculated as a fraction of runoff that ranges from $0-1 ; 0$ being no water available and 1 being maximum water availability for plants. ins is assumed to be in a linear relationship with latitude, $f_{\text {lat }}{ }^{24}$.

$$
\text { ins }=150+250 f_{\text {lat }}
$$

Insolation increases as latitudes get closer to the equator and decrease as they go towards the poles. The model substitutes PAR (Photosynthetically Active Radiation) for insolation. $\sigma_{c}, s, c_{1}, c_{2}$ are taken from Sitch et al. (2003) and written as:

$$
\begin{gathered}
\sigma_{c}\left[1-\frac{\left(c_{2}-s\right)}{\left(c_{2}-\theta s\right)}\right]^{0.5} \\
c_{1}=\alpha f_{\text {temp }} \frac{\left(p_{i}-\Gamma_{*}\right)}{\left(p_{i}-2 \Gamma_{*}\right)} \\
c_{2}=\frac{\left(p_{i}-\Gamma_{*}\right)}{\left(p_{i}-K_{C}\left(1+\frac{p O_{2}}{K_{O}}\right)\right)} \\
s=\left(\frac{24}{h}\right) a
\end{gathered}
$$
specifies the degree of co-limitation by light and Rubisco activity; $h$ is the daylight hours 

compensation point given by:

$$
\Gamma_{*}=\frac{p O_{2}}{2 \tau}
$$

where $\mathrm{pO}_{2}$ is the ambient partial pressure of $\mathrm{O}_{2}(\mathrm{~Pa})$ taken from Krause et al., 2018 (Table $\mathrm{S} 2)$, and $p_{i}$ is the intracellular partial pressure of $\mathrm{CO}_{2}(\mathrm{~Pa})$ calculated using

$$
p_{i}=\lambda p_{a}
$$

$p_{a}$, is the ambient partial pressure of $\mathrm{CO}_{2}$ and $\lambda$, a positive parameter that represents the stomata keeping a constant ratio of intracellular to ambient $\mathrm{CO}_{2}$. The ratio ranges from 0.60.8 therefore a constant of 0.8 for $\mathrm{C}_{3}$ plants is used (Haxeltine and Prentice 1996, Sitch et al. 2003).

Temperature dependent kinetic parameters $K_{C}, K_{O}$ and $\tau$ are modelled using

$$
k=k_{25} Q_{10}^{0.1(T-25)}
$$

taken from Haxeltine and Prentice (1996). $K_{C}, K_{O}$ are the Michaelis constants for $\mathrm{CO}_{2}$ and $\mathrm{O}_{2}$ inhibition in the Rubisco reaction. $k_{25}$ is the parameter value at $25^{\circ} \mathrm{C}$ and $Q_{10}$ is the relative change in parameter for every $10^{\circ} \mathrm{C}$ change in temperature.

Initial carbon allocation to leaves $C_{\text {leaf }}\left(\mathrm{g} \mathrm{C} / \mathrm{m}^{2} / \mathrm{year}\right)$ of the carbon acquired via photosynthesis is calculated using:

$$
C_{\text {leaf }}=l_{\text {max }} P
$$

using a leaf carbon allocation ratio, $l_{\max }$. Under constant conditions, an allocation ratio of 0.88 is given towards shoot growth ${ }^{38}$. Within angiosperms and gymnosperms, allocation towards leaves has a maximum of approximately $0.75{ }^{39}$ which decreases with plant growth as more biomass is allocated towards the stems. The maximum value is used throughout 
therefore assuming $75 \%$ of photosynthetic carbon is stored in the leaves. Carbon accumulation overtime is then calculated by:

$$
C_{\text {leaf }(n+1)}=C_{\text {leaf }(n)}\left(1-f_{\text {leaf }}\right)+l_{\max } N P P
$$

where $f_{\text {leaf }}$ represents leaf turnover for each plant type (Table S1). Initial leaf carbon allocation is calculated using photosynthesis however to calculate leaf carbon accumulation for the global population of plants, NPP is used thereafter.

$$
N P P=\left(1-R_{\text {growth }}\right)\left(P-R_{\text {leaf }}\right)
$$

NPP is the net primary productivity ( $\mathrm{g} \mathrm{C} / \mathrm{m}^{2} /$ year). Carbon is acquired by photosynthesis and lost through growth respiration $R_{\text {growth }}$ and maintenance respiration, $R_{\text {leaf }} .25 \%$ of total NPP goes towards $R_{\text {growth }}$ (Sitch et al. 2003) whereas $R_{\text {leaf }}$ is calculated using:

$$
\begin{gathered}
R_{\text {leaf }}=r\left(\frac{C_{\text {leaf }}}{\text { cn }_{\text {leaf }}}\right) g(T) \\
g(T)=\exp \left[308.56\left(\frac{1}{52.02}-\frac{1}{T+46.02}\right)\right]
\end{gathered}
$$

$R_{\text {leaf }}$ depends on a modified Arrhenius equation, $g(T)$, tissue respiration, $r$, and leaf specific $\mathrm{C}: \mathrm{N}$ ratio, $c n_{\text {leaf }} . r$ is the plant-type specific respiration rate $(\mathrm{g} \mathrm{C} / \mathrm{g} \mathrm{N} / \mathrm{year})$ (Table $\left.\mathrm{S} 1\right)$. Values for the tropical and boreal plant types are taken from Sitch et al. (2003) and modified for the temperate plant-type. It follows the observation that plants of warmer environments have a lower respiration rate at any given temperature compared to plants from colder environments (Sitch et al., 2003).

Biomass, $B,\left(\mathrm{~g} \mathrm{C} / \mathrm{m}^{2} /\right.$ year $)$ is the reservoir of carbon with inflow from leaf carbon accumulation and we assume a constant $10 \%$ outflow, representing combined biomass degradation processes, and chosen to reproduce overall modern biomass. 


$$
B_{(n+1)}=B_{(n)}+\left(C_{l e a f(n)}-0.1 B_{(n)}\right)
$$

273 Initial biomass $B_{(1)}$ is set at $250 \mathrm{~kg} \mathrm{C} / \mathrm{m}^{2}$ which serves as the baseline for biomass

274 growth/loss.

\section{Figures with caption}

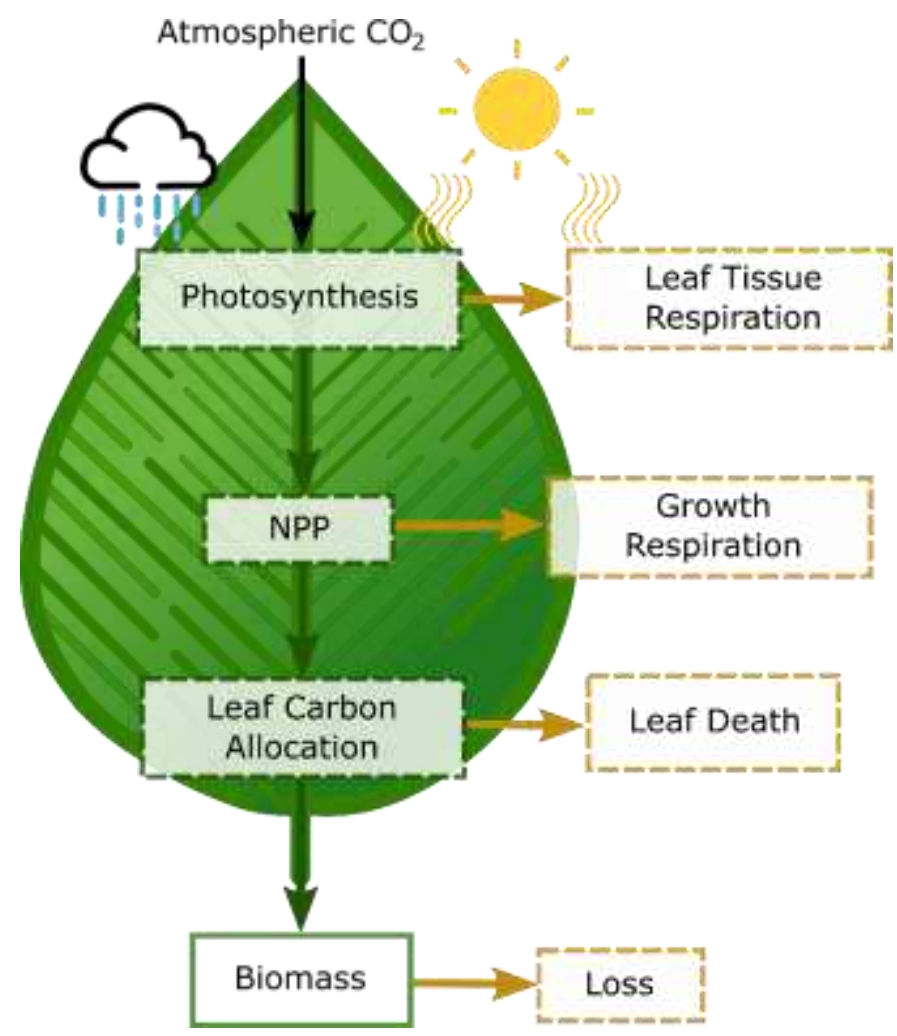

278 Figure 1. Model flowchart. Each arrow depicts the flow of carbon, green indicates carbon is 279 preserved within the system while brown indicates its departure. Note: the model uses a single biomass pool and losses associated with respiration and leaf death affect the growth of the biomass pool. Processes are given in dashed boxes whereas reservoirs are presented in bold boxes. Processes that are affected by temperature (red lines), insolation (sun) and water stress (blue drops) are indicated. NPP: net primary productivity. 

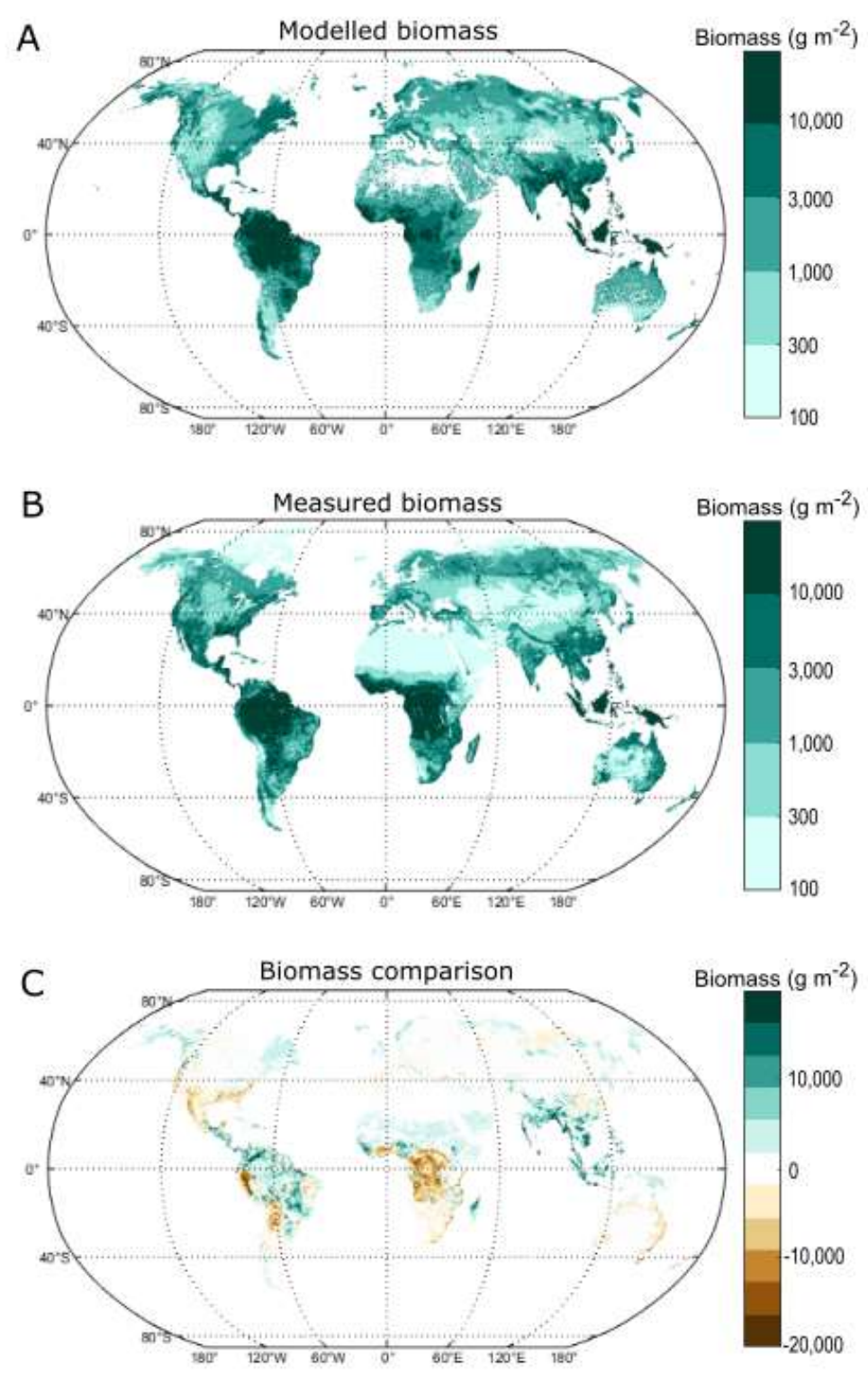

285 Figure 2. Modelled and measured biomass comparison. The model predicts a reasonable

286 approximation of current biomass. (A) Actual above- and below-ground global biomass for the year

2872000 obtained from CDIAC ${ }^{25}$. (B) Model predicted biomass given average temperatures (between

288 1900-1990) and 'best estimation' of yearly runoff from the year 2000. (C) Areas of over-prediction

289 (green) and under-prediction (brown) of biomass. 
A

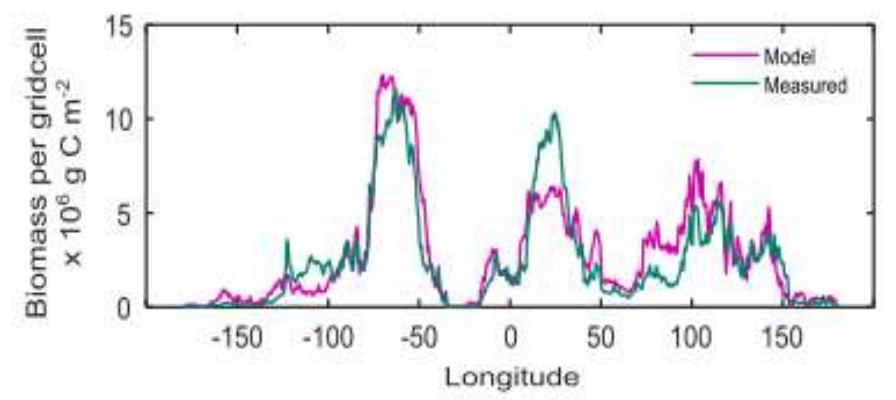

B

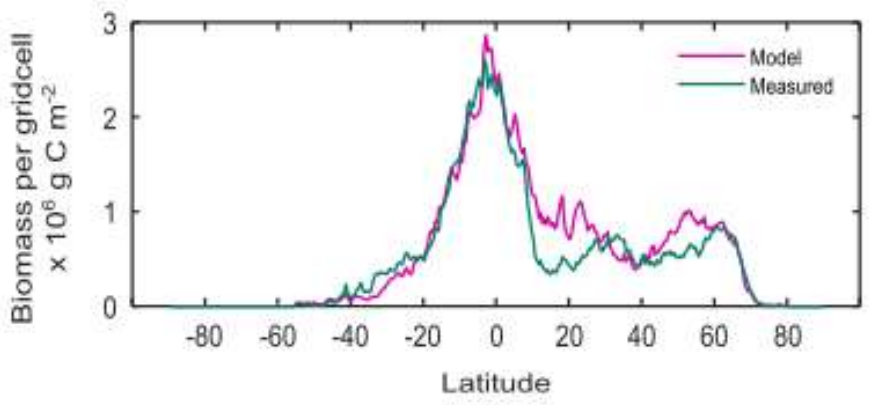

C

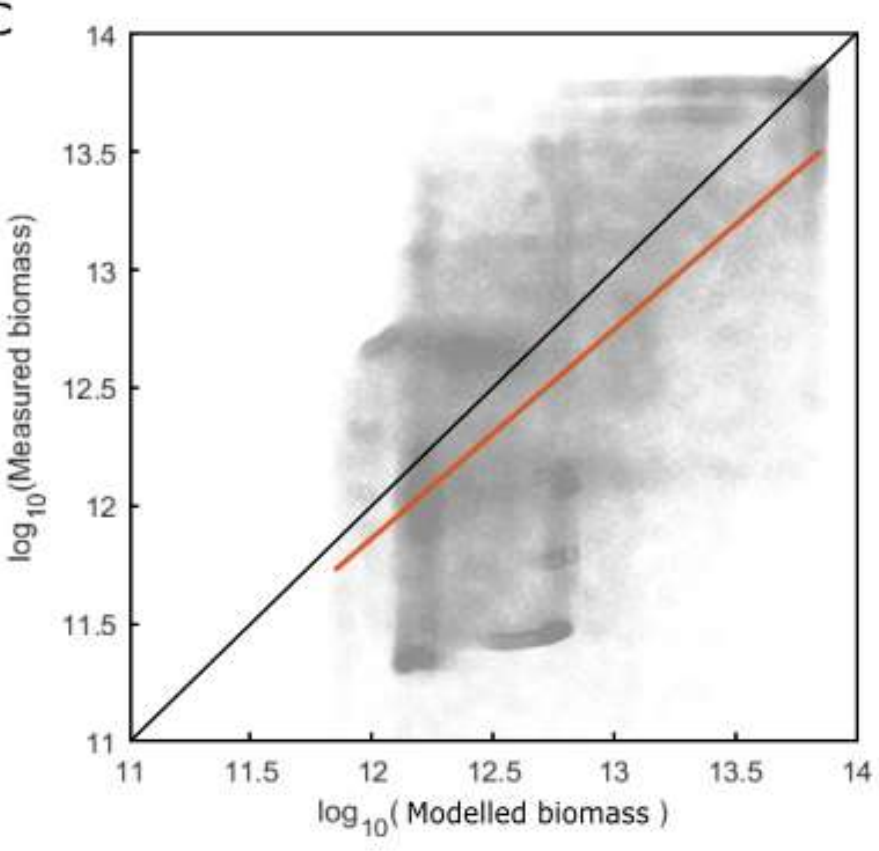

292 Figure 3. Further modelled and measured biomass comparison. (A) Sum of biomass between modelled (pink line) and measured (green line) data ${ }^{25}$ show overall longitude $\left(-180^{\circ} \mathrm{W}\right.$ to $\left.180^{\circ} \mathrm{E}\right)$ and latitude $\left(-90^{\circ} \mathrm{S}\right.$ to $\left.90^{\circ} \mathrm{N}\right)$ biomass patterns are preserved. Highest global plant biomass is present closer to the equator $\left(0^{\circ}\right.$ Latitude). (B) Model predicted and measured biomass show a linear relationship

296 (orange line) with an R-squared value of 0.408 in log space, or 0.606 in linear space. A 1:1 line is 297 shown for comparison in black. 

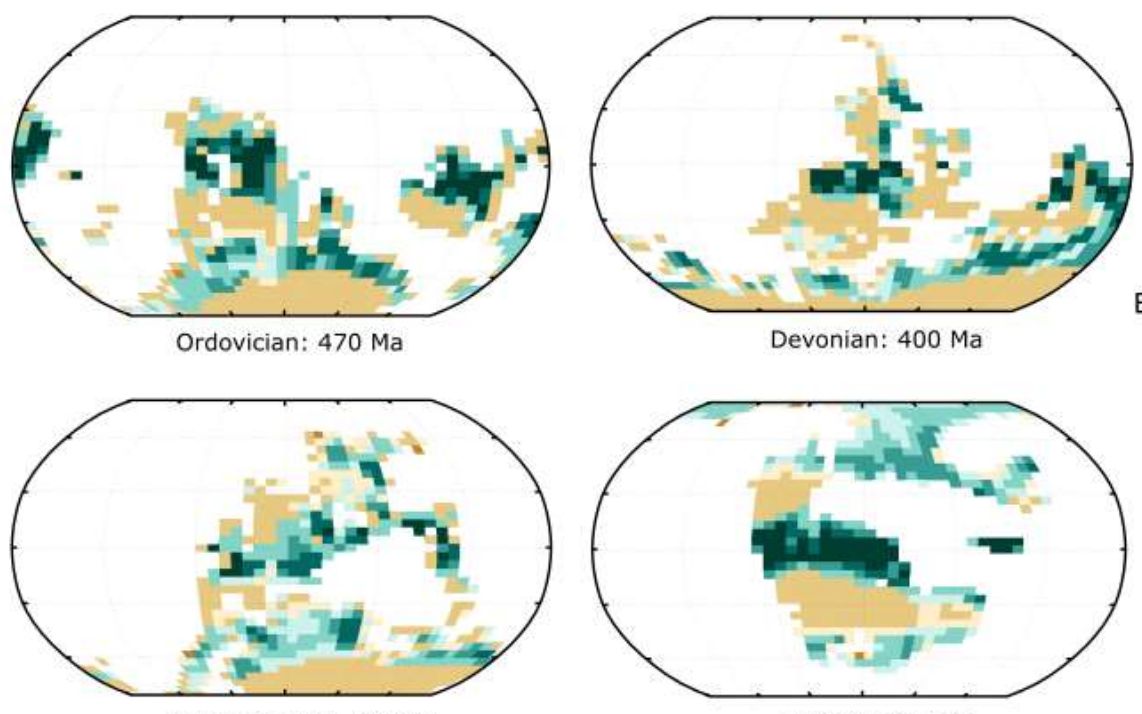

Biomass $\left(\mathrm{g} \mathrm{m}^{-2}\right)$

Carboniferous: $300 \mathrm{Ma}$

Jurassic: $200 \mathrm{Ma}$
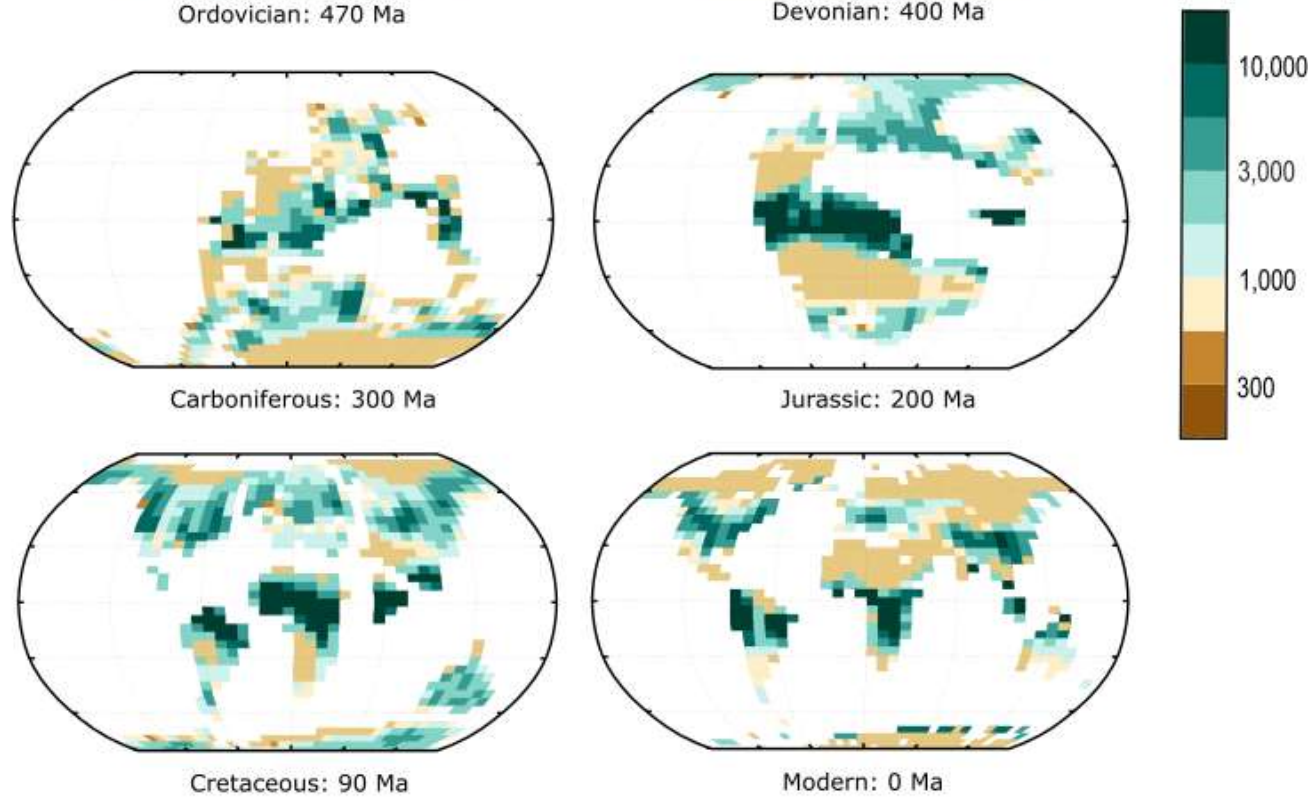

300 Figure 4. Global potential biomass maps during the Phanerozoic. Maps showing a selection of the potential biomass predictions from this model. Ma: millions of years. 

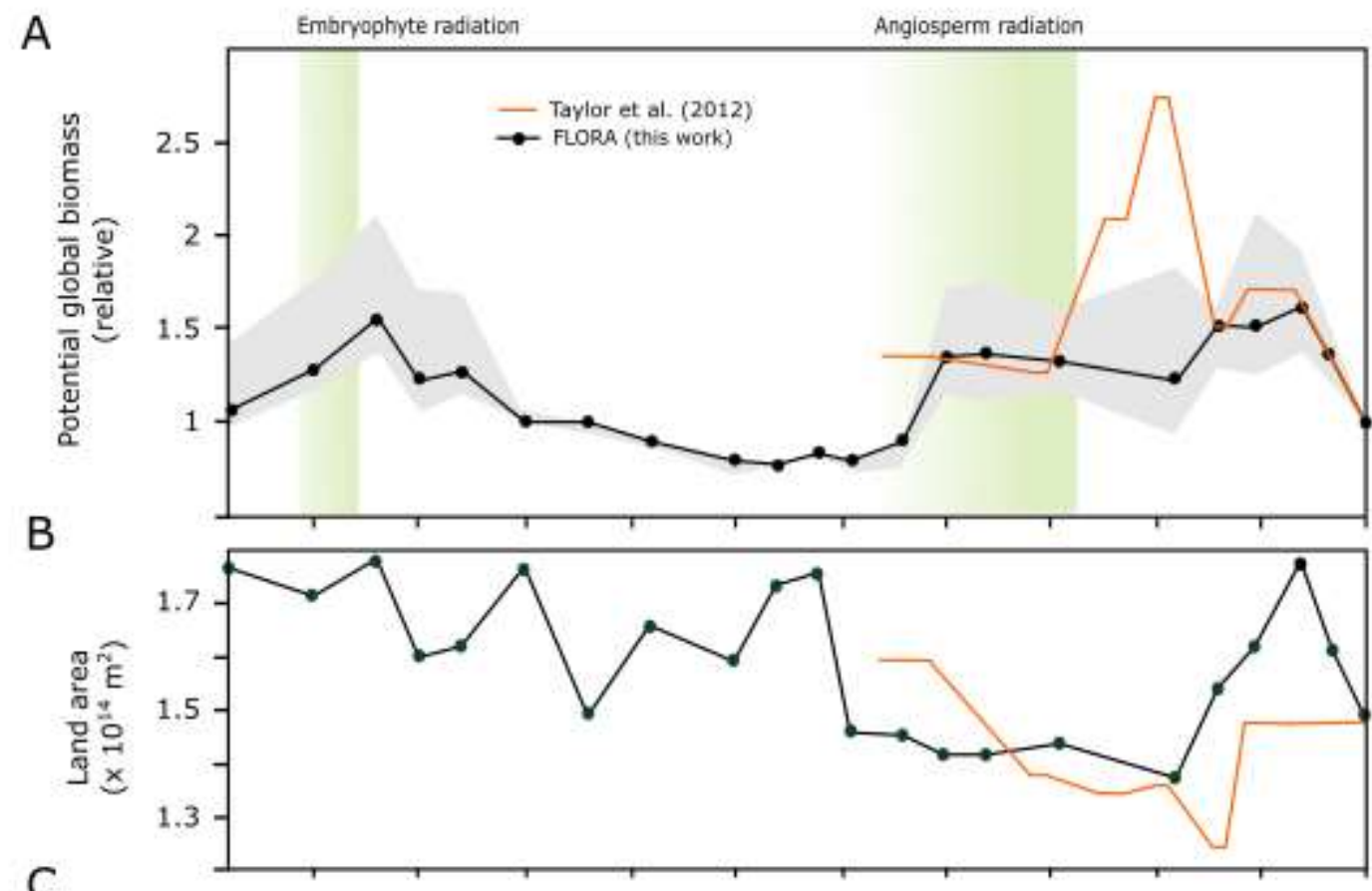

C
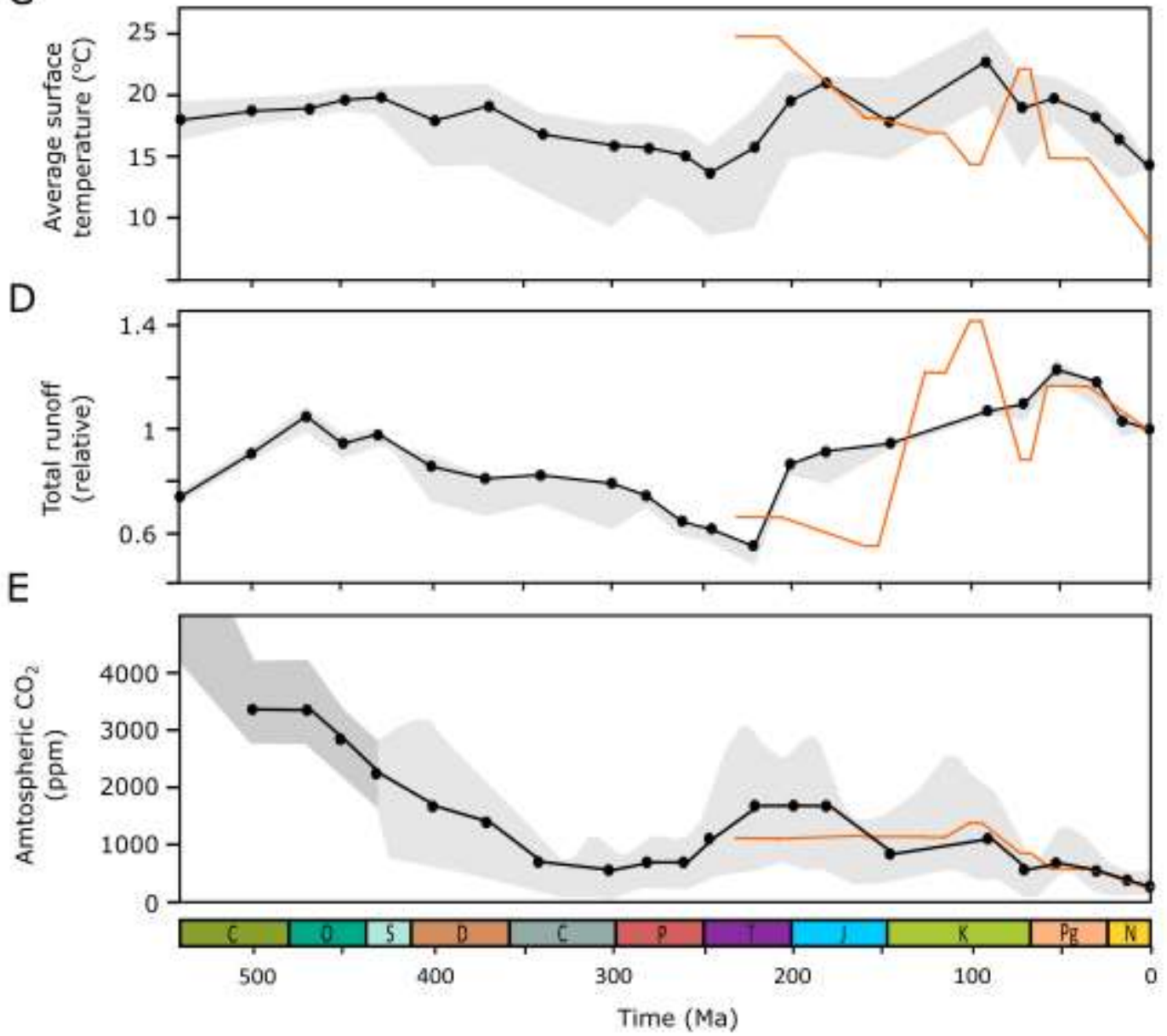

Figure 5. Global potential relative biomass, runoff, average temperature and $\mathrm{CO}_{2}$ level during the Phanerozoic (540-0 Ma). Proxies (temperature and runoff) depend on the predicted $\mathrm{CO}_{2}$ level. 
Grey area represents the $\min / \max$ values obtained at the $\min / \max \mathrm{CO}_{2}$ level. Time periods are highlighted at the bottom of the figure. Parameters and biomass used in Taylor et al. 2012 are shown in orange; the length of the solid line represents time periods used. (A) Relative biomass over time (kg $\mathrm{C}$ relative to present). Green highlights show predicted origin times: $\mathrm{Em}=$ embryophyte, $\mathrm{Ang}=$ of global runoff $\left(\mathrm{mm} /\right.$ year) and average temperature $\left({ }^{\circ} \mathrm{C}\right)$ overtime given specific $\mathrm{CO}_{2}$ levels. Data taken from Godderis et al. 2014. (E) Average $\mathrm{CO}_{2}$ level (ppm, yellow line). An approximate $\mathrm{CO}_{2}$ value (red dot) for each time period was chosen for the climate model. Dark grey area: predicted $\mathrm{CO}_{2}$ level chosen from a combination of COPSE and GEOCARBSULF model. Data taken from Mills et al. 2019.

\section{References}

1. Beerling, D. J. \& Berner, R. A. Feedbacks and the coevolution of plants and atmospheric CO 2. vol. 102 www.pnas.orgcgidoi10.1073pnas.0408724102 (2005).

2. Porada, P. et al. High potential for weathering and climate effects of non-vascular vegetation in the Late Ordovician. Nat. Commun. 7, 1-13 (2016).

3. Boyce, C. K. \& Lee, J.-E. Plant Evolution and Climate Over Geological Timescales. (2017)

4. Sauquet, H. et al. The ancestral flower of angiosperms and its early diversification. Nat.

5. Algeo, T. J., Berner, R. A., Maynard, J. B. \& Scheckler, S. E. Late Devonian oceanic anoxic events and biotic crisis: 'rooted' in the evolution of vascular land plants?' GSA Today $\mathbf{5}$, (1995).

6. Berner, R. A. The Rise of Plants and Their Effect on Weathering and Atmospheric CO2. 
Science (80-. ). 276, 544-546 (1997).

7. Lenton, T. M., Crouch, M., Johnson, M., Pires, N. \& Dolan, L. First plants cooled the Ordovician. Nat. Geosci. 5, 86-89 (2012).

8. Lenton, T. M. et al. Earliest land plants created modern levels of atmospheric oxygen. Proc. Natl. Acad. Sci. U. S. A. 113, 9704-9709 (2016).

9. Epihov, D. Z. et al. N2-fixing tropical legume evolution: a contributor to enhanced weathering through the Cenozoic? Proc. R. Soc. B Biol. Sci. 284, (2017).

10. Retallack, G. J. Cenozoic Expansion of Grasslands and Climatic Cooling. https://doi.org/10.1086/320791 109, 407-426 (2015).

11. Flexas, J., Gallé, A., Galmés, J., Ribas-Carbo, M. \& Medrano, H. The Response of Photosynthesis to Soil Water Stress. Plant Responses to Drought Stress From Morphol. to Mol. Featur. 129-144 (2012) doi:10.1007/978-3-642-32653-0_5.

12. Taylor, L. L., Banwart, S. A., Valdes, P. J., Leake, J. R. \& Beerling, D. J. Evaluating the effects of terrestrial ecosystems, climate and carbon dioxide on weathering over geological time: A global-scale process-based approach. Philos. Trans. R. Soc. B Biol. Sci. 367, 565-582 (2012).

13. Otto-Bliesner, B. L. Continental drift, runoff, and weathering feedbacks: Implications from climate model experiments. J. Geophys. Res. Atmos. 100, 11537-11548 (1995).

14. Chaboureau, A. C., Sepulchre, P., Donnadieu, Y. \& Franc, A. Tectonic-driven climate change and the diversification of angiosperms. Proceedings of the National Academy of Sciences of the United States of America vol. 111 14066-14070 (2014).

15. Fiz-Palacios, O., Schneider, H., Heinrichs, J. \& Savolainen, V. Diversification of land plants: insights from a family-level phylogenetic analysis. BMC Evol. Biol. 2011111 11, 1-10 (2011).

16. Goddéris, Y., Donnadieu, Y., Le Hir, G., Lefebvre, V. \& Nardin, E. The role of palaeogeography in the Phanerozoic history of atmospheric $\mathrm{CO} 2$ and climate. Earth-Science Rev. 128, 122-138 (2014).

17. Tabor, C. R., Feng, R. \& Otto-Bliesner, B. L. Climate Responses to the Splitting of a Supercontinent: Implications for the Breakup of Pangea. Geophys. Res. Lett. 46, 6059-6068 (2019). 
18. Donnadieu, Y., Goddéris, Y. \& Bouttes, N. Exploring the climatic impact of the continental vegetation on the Mezosoic atmospheric CO2 and climate history. Clim. Past 5, 85-96 (2009).

19. Sitch, S. et al. Evaluation of ecosystem dynamics, plant geography and terrestrial carbon cycling in the LPJ dynamic global vegetation model. Glob. Chang. Biol. 9, 161-185 (2003).

20. Zhang, Y., Xu, M., Chen, H. \& Adams, J. Global pattern of NPP to GPP ratio derived from MODIS data: effects of ecosystem type, geographical location and climate. Glob. Ecol. Biogeogr. 18, 280-290 (2009).

21. Luyssaert, S. et al. $\mathrm{CO} 2$ balance of boreal, temperate, and tropical forests derived from a global database. Glob. Chang. Biol. 13, 2509-2537 (2007).

22. Fekete, B. M., Vorosmarty, C. J. \& Grabs, W. Global, Composite Runoff Fields Based on Observed River Discharge and Simulated Water Balances. https://www.compositerunoff.sr.unh.edu//html/paper/ReportA4.pdf (2000).

23. Mitchell, T. D. \& Jones, P. D. An improved method of constructing a database of monthly climate observations and associated high-resolution grids. Int. J. Climatol. 25, 693-712 (2005).

24. Meek, D. W., Hatfield, J. L., Howell, T. A., Idso, S. B. \& Reginato, R. J. A Generalized Relationship between Photosynthetically Active Radiation and Solar Radiation1. Agron. J. 76, 939-945 (1984).

25. Ruesch, A. \& Holly, K. G. New IPCC Tier-1 Global Biomass Carbon Map For the Year 2000. (2008).

26. Jacob, R. L. Low frequency variability in a simulated atmosphere ocean system. (University of Wisconsin, 1997).

27. Scotese, C. R., Song, H., Mills, B. J. W. \& van der Meer, D. G. Phanerozoic paleotemperatures: The earth's changing climate during the last 540 million years. EarthScience Rev. 215, 103503 (2021).

28. Oliver, M. J., Velten, J. \& Mishler, B. D. Desiccation Tolerance in Bryophytes: A Reflection of the Primitive Strategy for Plant Survival in Dehydrating Habitats? Integr. Comp. Biol. 45, 788-799 (2005).

29. Edwards, D. Xylem in early tracheophytes. Plant. Cell Environ. 26, 57-72 (2003). 
30. Morris, J. L. et al. The timescale of early land plant evolution. Proc. Natl. Acad. Sci. U. S. A. 115, E2274-E2283 (2018).

31. Matsunaga, K. K. S. \& Tomescu, A. M. F. Root evolution at the base of the lycophyte clade: insights from an Early Devonian lycophyte. Ann. Bot. 117, 585-598 (2016).

32. Raven, J. A. \& Edwards, D. Roots: evolutionary origins and biogeochemical significance. $J$. Exp. Bot. 52, 381-401 (2001).

33. Magallón, S., Hilu, K. W. \& Quandt, D. Land plant evolutionary timeline: Gene effects are secondary to fossil constraints in relaxed clock estimation of age and substitution rates. Am. $J$. Bot. 100, 556-573 (2013).

34. Barba-Montoya, J., Reis, M. dos, Schneider, H., Donoghue, P. C. J. \& Yang, Z. Constraining uncertainty in the timescale of angiosperm evolution and the veracity of a Cretaceous Terrestrial Revolution. New Phytol. 218, 819-834 (2018).

35. Donnadieu, Y. et al. A GEOCLIM simulation of climatic and biogeochemical consequences of Pangea breakup. Geochemistry, Geophys. Geosystems 7, n/a-n/a (2006).

36. Haxeltine, A. \& Prentice, I. C. A General Model for the Light-Use Efficiency of Primary Production. Ecology vol. 10 (1996).

37. Krause, A. J. et al. Stepwise oxygenation of the Paleozoic atmosphere. Nat. Commun. 201891 9, 1-10 (2018).

38. Chen, J. L. \& Reynolds, J. F. A coordination model of whole-plant carbon allocation in relation to water stress. Ann. Bot. (1997) doi:10.1006/anbo.1997.0406.

39. Poorter, H. et al. Biomass allocation to leaves, stems and roots: meta-analyses of interspecific variation and environmental control. New Phytol. 193, 30-50 (2012).

\section{Acknowledgements (optional)}

We are grateful to Sitch et al. (2003) for the careful description of the equations in the LPJDGVM which allowed us to base our model on their work. KG, KJF, SAB and BJWM are funded by the UK Natural Environment Research Council (NE/S009663/1). KJF is supported 

408092731

\section{Ethics declarations}

422

423 No competing interests.

424 


\section{Supplementary Files}

This is a list of supplementary files associated with this preprint. Click to download.

- GurungetalSI.pdf 